\title{
Comparative Study of Hard and Soft Switched Full Bridge DC-DC Converter for Photovoltaic Application
}

\author{
Shamkumar B. Chavan \\ Shivaji University, \\ Vidya Nagar, Kolhapur \\ Maharashtra, India 416004
}

\author{
Mahesh S. Chavan \\ Shivaji University \\ KIT College of Engineering, \\ Kolhapur, Maharashtra, India
}

\begin{abstract}
This paper aims to compare the performance of two control schemes viz. hard switched and phase shifted control scheme for full bridge DC-DC converter used in photovoltaic application .The proposed converters are designed for $650 \mathrm{~W}$ photovoltaic input power. Voltage and current waveforms at various test points like across IGBT, transformer primary and secondary, output etc. are compared and results are presented. From results it can be seen that in phase shift control simultaneous transition of voltage across IGBT and current through IGBT is avoided hence reduction in switching losses, $\mathrm{dv} / \mathrm{dt}$, di/dt effects and EMI effects can be achieved. At higher switching frequencies phase shift control scheme is meritorious over hard switched control scheme.
\end{abstract}

\section{General Terms}

Full bridge DC-DC converter, hard and soft switching

\section{Keywords}

phase shift full bridge DC-DC converter; phase shift v/s hard switched control; phase shifted full bridge in photovoltaic application

\section{INTRODUCTION}

Full bridge DC-DC converters are preferred for medium to large power applications. In hard switched control scheme power switches are switched ON and OFF instantaneously creating RF noise, di/dt and dv/dt effects, due to hard switching life time of power switches decreases. Higher power device operating frequency reduces size of magnetic devices like transformer, inductor etc. Therefore now-a-days research is focused on use of higher operating frequency to obtain size reduction. However use of higher frequency creates issues like higher RF noise, EMI, switching losses, lowered reliability of power devices etc. Therefore soft switched control scheme has attracted researchers to operate devices on higher frequency. References [1]-[6] presented here focus on information and design aspects of soft switching converters while [7]-[11] focus on reliability issues of semiconductor power switches and power processing circuitry. J.A.Sabate et al presented detail operation, design procedure, equations and loss analysis of ZVS full bridge DC-DC converter in [1]. In ZVS phase shift is introduced between two legs hence the switch capacitance get discharged through leakage inductance, first antiparallel diode conducts and then power switch conducts. According to authors ZVS provides several advantages like lowered switching losses, less device stress, absence of snubbers and at higher switching frequency higher power and efficiency can also be obtained.

Reference [2] deals with design and analysis of power conditioning system between fuel cell and utility line. Design considerations, operation, analysis, simulation and experimental results for soft switching DC-DC converters are presented here in detail. Considering the need of higher voltage gain converters for PV applications Jiang et al [3] have developed a $100 \mathrm{~W}$ phase shifted full bridge DC-DC converter in which voltage doubler is added to the converter. External inductor and transformer provides ZVS, $93 \%$ efficiency is obtained here. A soft switched multi-phase boost converter is proposed in [4] to focus on problems like life time increment of PV array and improvement in system efficiency. The MPPT scheme presented here is able to track multiple peaks. Reduction in ripple contents and in switching losses is observed here. Reference [5] deals with soft switching technique which is based on secondary side LC resonant principle. In ref. [6] coaxial and planar high frequency power transformers for converters in PV systems are described. Flux and eddy current analysis is done here by using FEM method. Power semiconductor switch failures effects, their diagnosis schemes and existing fault tolerant schemes are discussed in ref.[7] . Yang et al carried out an industrial survey [8] and found that power switches are very brittle and troublesome components in the converters used for industrial applications. In ref.[9] a model based scheme is presented for detection of open circuit power switch faults in full bridge DC-DC converters. References [10]-[11] present reliability oriented assessment of converters and power processing stages in photovoltaic applications.

The aim of this paper is to simulate and compare full bridge DC-DC converters with hard switching and soft switching control schemes. The converter is designed for photovoltaic application.

\section{TOPOLOGY COMPARISON}

Figure $1 \mathrm{~A}$ and $1 \mathrm{~B}$ shows topologies for hard switched and phase shifted full bridge DC-DC converter. Leakage inductance shown in fig. $1 \mathrm{~B}$ is internally adjusted in transformer. In hard switched full bridge DC-DC converter transformer with zero leakage inductance is required.

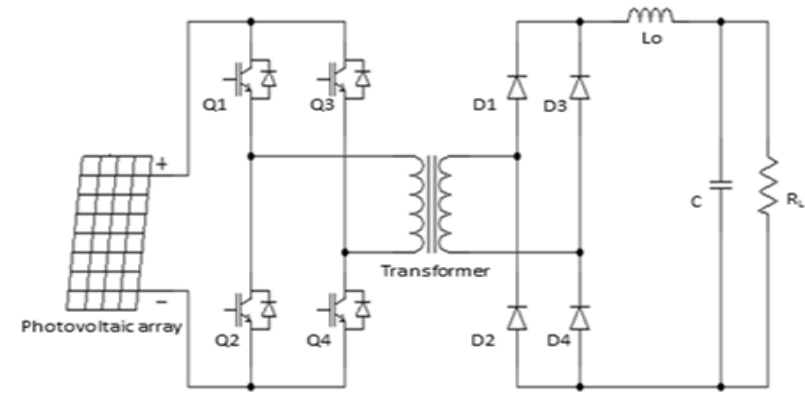




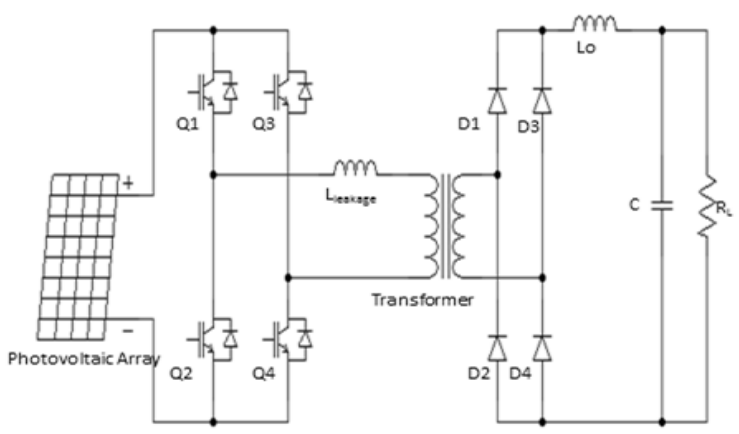

Figure 1- a) hard switched full bridge DC-DC converter and b) soft switched full bridge DC-DC converter

For hard switched converter IGBTs conduct diagonally while for phase shift converters a phase shift is introduced between the left and right legs; converter duty cycle is determined from this phase shift which is given by [12],

Duty Cycle $=0.5-\Delta \Phi / 2 \Pi$

Figure $2 \mathrm{~A}$ and $2 \mathrm{~B}$ shows gate pulse schemes for hard and phase shifted full bridge DC-DC converters. In phase shifted converter power switches are gated at different intervals as shown in fig. $2 \mathrm{~B}$.

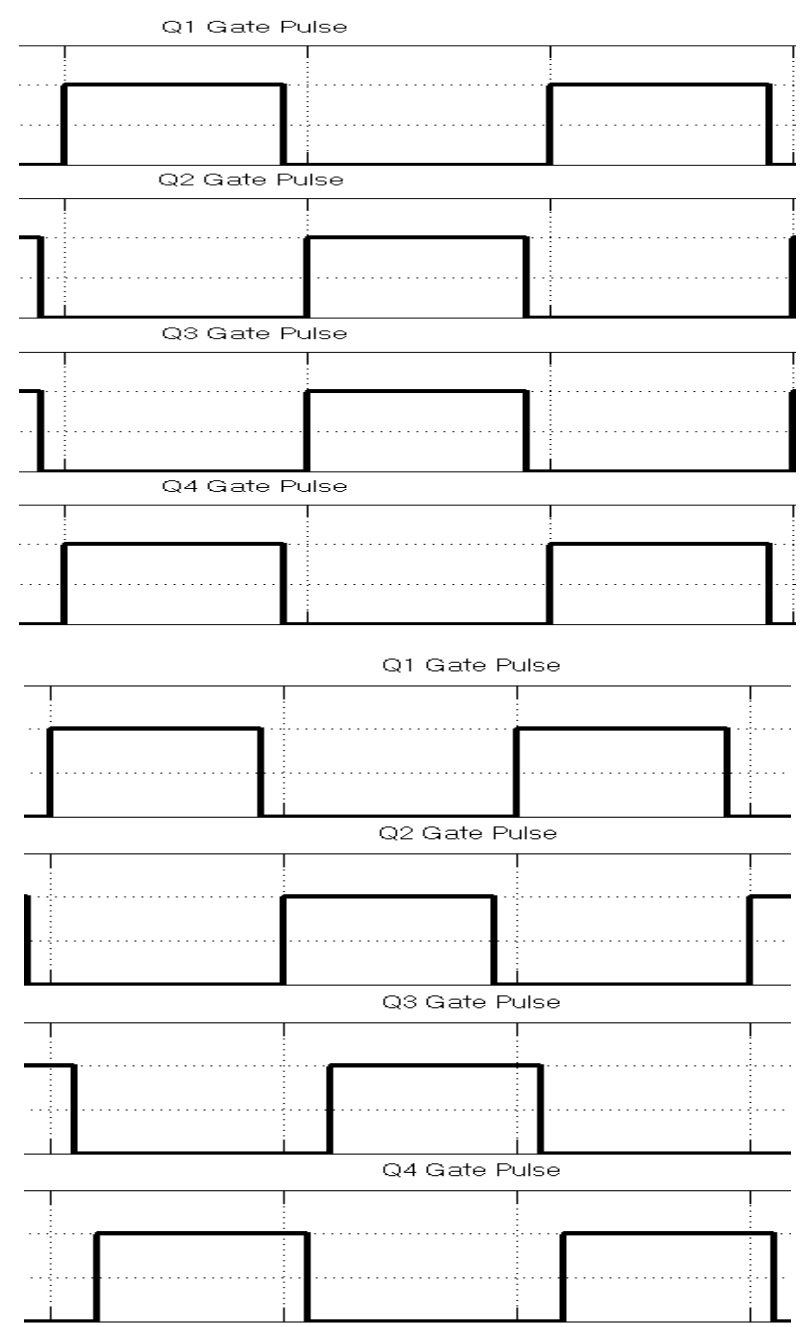

Figure 2- Applied gate pulses for a) hard switched converter and b) phase shifted converter

\section{RESULTS AND DISCUSSION}

In this experiment simulation models of hard and phase shifted full bridge DC-DC converters are created in SimPowerSystems toolbox of MATLAB 2013b and performance of both is assessed. Here IGBTs are used and soft switching is achieved by means of device capacitance and leakage inductance of transformer.

Figure $3 \mathrm{~A}$ and $3 \mathrm{~B}$ shows the waveforms obtained at primary and secondary of transformer.
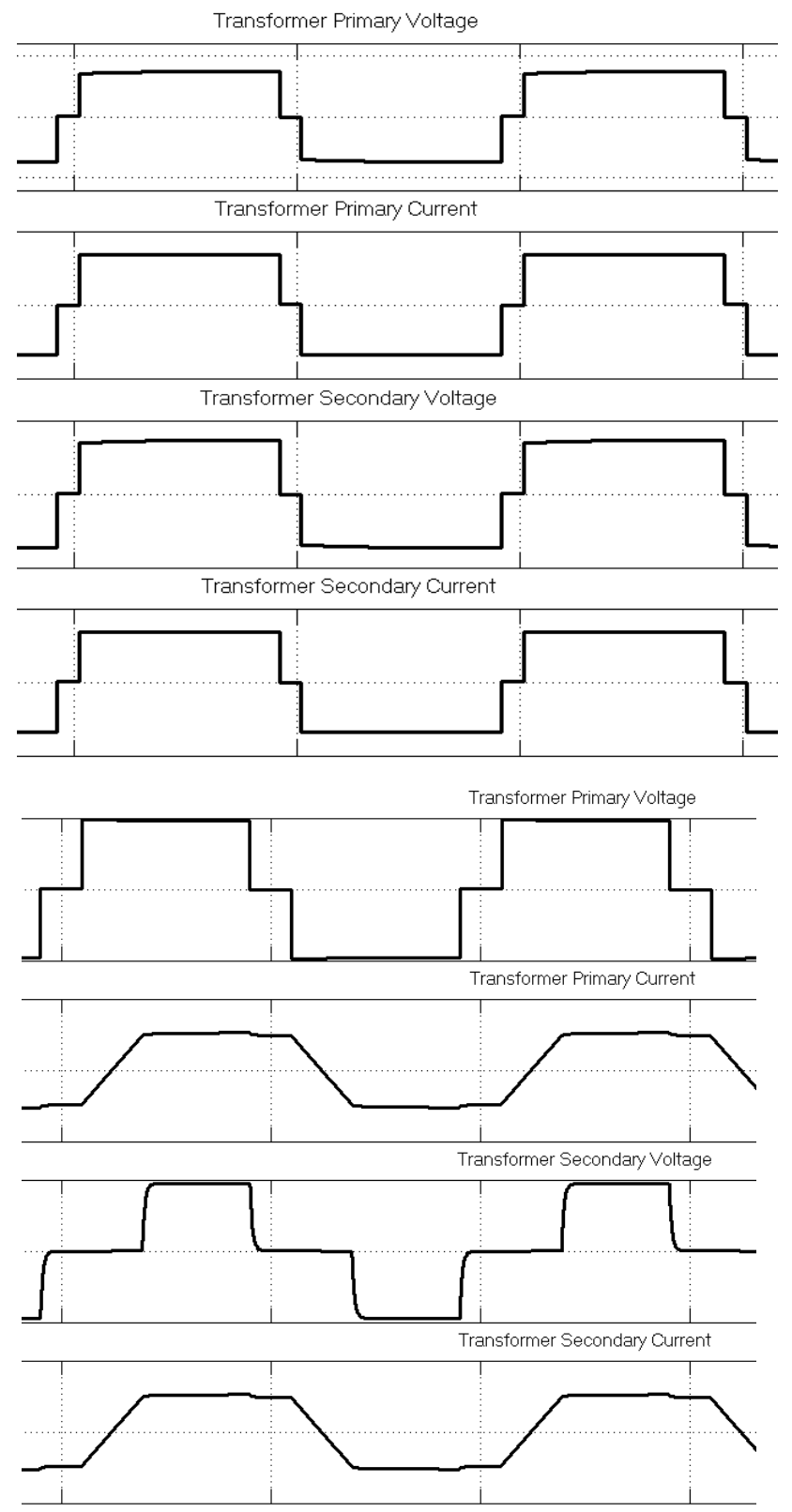

Figure 3- Transformer primary voltage, current and secondary voltage, current a) hard switched converter b) phase shifted converter

In hard switched converter transformer primary voltage, current and secondary voltage, current are in phase i.e. switching takes place instantaneously. In phase shifted converter such instantaneous switching is absent. 
Figures $4 \mathrm{~A}$ and $4 \mathrm{~B}$ shows voltage across IGBT and current through IGBT.
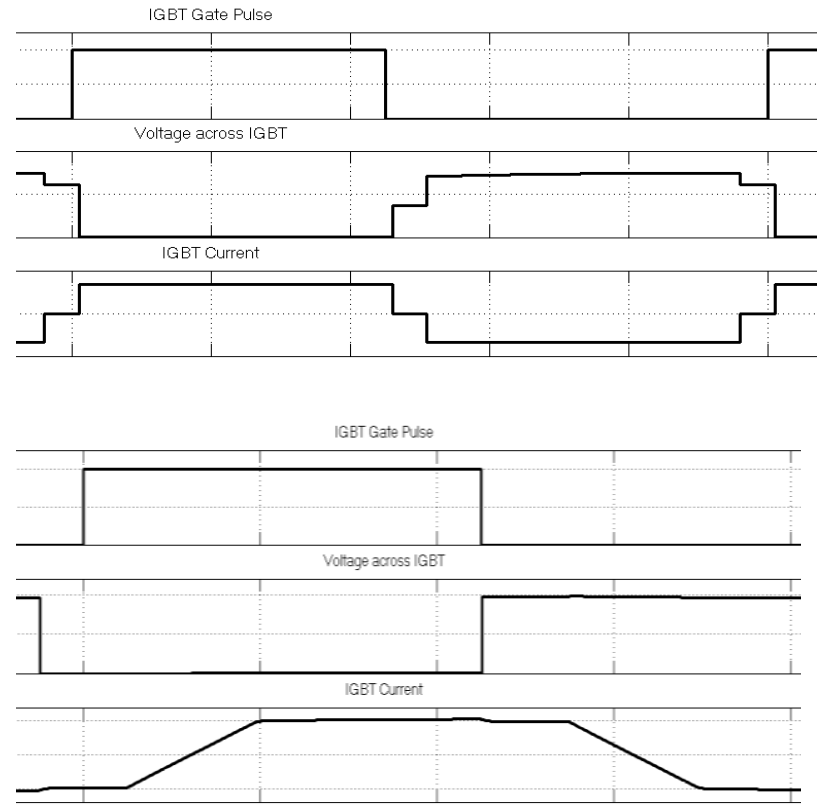

Figure 4- Voltage across IGBT and current through IGBT Q1 a) hard switching and b) phase shifted converter

From fig. $4 \mathrm{~A}$ and $4 \mathrm{~B}$ it is clear that in hard switched topology voltage and current instantaneously changes in IGBT while in phase shifted topology instantaneous changes in voltage and current are absent. This is ZVS scheme in which voltage across IGBT reduces to zero before application of gate pulse. Current passing through IGBT is also delayed. It can be seen that simultaneous switching of voltage and current waveforms has been avoided here. Thus reduction in EMI, reduction in switching losses and improvement in reliability aspects can be obtained in phase shift controlled topology.

Figure 5A and 5B shows output voltage and current waveforms of both topologies.

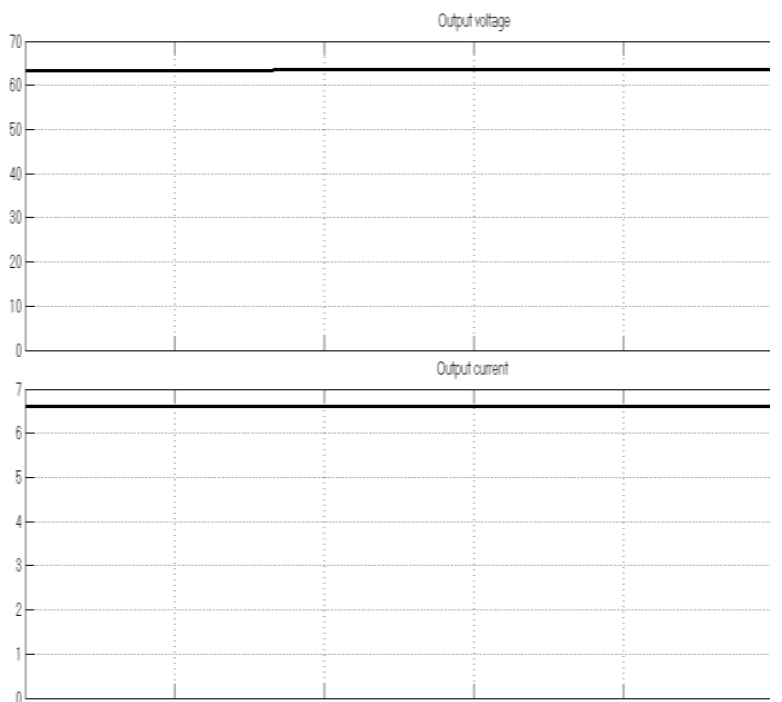

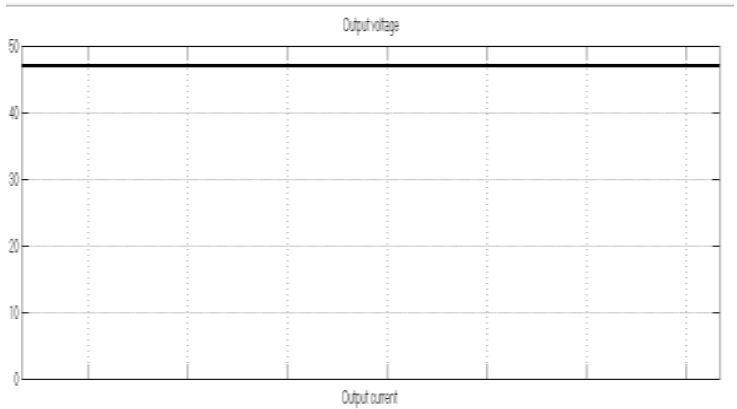

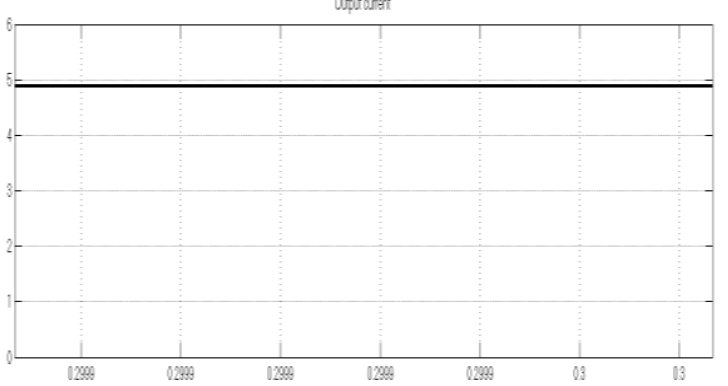

Figure 5- Output voltage and current a) hard switching and b) phase shift switching

Specifications of the converter are given in table 1 .

Table 1- Converter specifications

\begin{tabular}{|l|l|}
\hline Component & Rating \\
\hline $\mathrm{V}_{\mathrm{PV}}$ & 97 Volts \\
\hline $\mathrm{I}_{\mathrm{PV}}$ & 7 Ampere \\
\hline $\mathrm{V}_{\text {output }}$ & $48 \mathrm{~V}$ \\
\hline $\mathrm{I}_{\text {output }}$ & $5 \mathrm{Ampere}$ \\
\hline $\mathrm{L}_{\text {filter }}$ & $4.8 \mathrm{mH}$ \\
\hline $\mathrm{R}_{\text {output }}$ & $9.6 \Omega$ \\
\hline $\mathrm{C}_{\text {filter }}$ & $2200 \mu \mathrm{F}$ \\
\hline Switching frequency & $10 \mathrm{kHz}$ \\
\hline Duty cycle & 0.45 \\
\hline
\end{tabular}

Transformer with correct leakage inductance should be designed. References [13]-[14] deal with transformer design issues.

\section{CONCLUSION}

Simulation results have shown that in phase shift converters simultaneous voltage and current transients in IGBT is avoided , further it softly switches the state hence it works in SOA. Thus at higher switching frequencies where size of magnetic components like transformer and inductor reduces greatly it is feasible to use phase shift control scheme. This will also reduce switching losses and EMI effect at higher frequencies. This will be helpful in reliability improvement of power switch.

Results have shown that lowered output voltage and current are the demerits of phase shift control scheme.

\section{ACKNOWLEDGMENT}

Authors are thankful to Department of Technology, Shivaji University Kolhapur for providing necessary facilities for this work. 


\section{REFERENCES}

[1] J.A.Sabate, V. Vlatkovic, R.B.Ridley, F.C. Lee, B.H.Chao, 1990, Design considerations for high voltage high power full bridge zero voltage switched PWM converter, IEEE.

[2] A.K.Rathore, 2008, High frequency transformer isolated power conditioning system for fuel cells to utility interface, Ph.D. Thesis, University of Victoriya.

[3] Y.Jiang, Z.Chen, J.Pan, X.I.Zhao, P. Lee, 2008, A novel phase shift full bridge converter with voltage doubler and decoupling integrated magnetics in PV system, Bulletin of Polish academy of sciences, Technical sciences, 56(3), pp- 285-293.

[4] G.Ramya, R.Ramaprabha, 2014, Performance enhancement of photovoltaic system using soft switched multi-phase boost converter, J. Electrical systems, 10(4) pp-381-391.

[5] Daisuke Tsukiyama, Y.Fukuda, S.Miyake, 2011, A new $98 \%$ soft switching full bridge DC-DC converter based on secondary side LC resonant principle for PV generation systems", IEEE PEDS 2011, Singapore, pp-1112-1119.

[6] J. Lu, D.Butler, 2010, High frequency transformers for DC/DC converter used in Solar PV system", Journal of Energy and Power Engineering, 4(1) ,David Publishing, 16.

[7] S.B.Chavan, M.S.Chavan, 2014, Power switch faults, diagnosis and tolerant schemes in converters of photovoltaic systems- A review, International journal of advanced research in electrical, electronics and instrumentation engineering, 3(9), pp- 11729-11737.
[8] Shaoyang Yang, Angus Bryant, Philip Maybap, Dawei Xing, Peter Tanve, 2011, An industry based survey of reliability in power electronics converters", IEEE transactions on industry applications, 47(3), pp.14411451

[9] S.B.Chavan, M.S.Chavan, 2014, A model based approach for fault diagnosis in converter of photovoltaic system, IEEE global conference on wireless computing and networking, pp.-112-115.

[10] Hugo Callega, Freddy Chan, Israel Uribe,2007, Reliability oriented assessment of a DC/DC converter for photovoltaic applications, IEEE Power Electronics Specialists Conference, pp. 1522-1527.

[11] Freddy Chan, Hugo CallejaGjumlich,2008, Reliability analysis of the power electronics stages in grid connected PV systems, Cientifica, 12(3), pp.149-155.

[12] M. Kazimierczuk, Pulse width modulated DC-DC power converters, Wiley publications, pp-325-360.

[13] B. Cougo, J. Kolar, 2012, Integration of leakage inductance in tape wound core transformers for dual active bridge converters, International conference of integrated power electronics systems, Germany.

[14] A. Abdul Razzak, S. Taib, I. Daut,2005, Design and development of high frequency high power transformer for renewable energy application, International conference on robotics, vision, information and signal processing, $\mathrm{pp}$ 375-379. 